investigación económica, vol. LXIX, 272, abril-junio de 2010, pp. 15-56

\title{
El significado de la pobreza: cuestiones de distribución y poder
}

\author{
Arthur MacEwan* \\ Cuando uso una palabra -dijo Humpty Dumpty, en tono más bien desdeñoso-, \\ significa exactamente lo que yo quiero que signifique -ni más ni menos. \\ La pregunta es-dijo Alicia- si puede hacer que las palabras \\ signifiquen tantas cosas diferentes. \\ A través del espejo. \\ Lewis Carroll.
}

\section{INTRODUCCIÓN}

La 'pobreza' es una palabra utilizada en muchos sentidos diferentes. El problema es que se trata de un concepto usado para definir una gran parte de la política económica, y, en tanto política económica tiene - o no tiene-impactos reales sobre la vida de las personas. De ahí que entender el significado de la pobreza sea una tarea importante.

Hoy en día, la pobreza, especialmente como se vive en las zonas de bajos ingresos del mundo, se ha convertido en el centro de un gran debate entre economistas y responsables de la política económica, y existen varias campañas en marcha para eliminar la pobreza, o, según el lema dice "hacer de la pobreza, historia”. El proyecto de las Metas de Desarrollo del Milenio de las Naciones

\footnotetext{
Manuscrito recibido en marzo de 2009; aceptado en enero de 2010.

* Departamento de Economía de la Universidad de Massachusetts en Boston, <arthur.macewan@umb. edu>. Una versión anterior del texto se presentó en Golden Jubilee Conference del Bangladesh Institute of Development Studies, "Development Prospects for Bangladesh: Emerging Challenges," Dhaka, diciembre 2 y 3 de 2007. El autor agradece los comentarios de dos dictaminadores anónimos de la revista. Traducción del inglés de Carlos Salas Páez; revisión técnica de Ignacio Perrotini.
} 
Unidas (MDM) está en el pináculo de estos esfuerzos. En estas campañas, la cuestión es la privación absoluta, y el estándar actual, ampliamente aceptado, define la pobreza como vivir con menos de 2 dólares por día y la extrema pobreza como vivir con menos de 1 dólar por día. Las cifras de 2 y 1 dólar por día están evaluadas al tipo de cambio de la paridad de poder de compra, en términos del poder adquisitivo de 1990. En términos actuales (2009) el equivalente sería definir la pobreza como el vivir con menos de 3.28 dólares por día, y la extrema pobreza como hacerlo con menos de 1.64 dólares por día. El Banco Mundial utiliza estas normas para reportar cada año sobre el número de personas que viven en la pobreza y en extrema pobreza, y las cifras del Banco son muy citadas. Una meta central de las MDM es reducir a la mitad el número de personas que viven por debajo del umbral de 1 dólar al día para el año 2015 . $^{1}$

Esta definición de la pobreza, en términos de privación absoluta, parece tener sentido. Cuando las personas no tienen acceso a las necesidades básicas -los alimentos, la vivienda, la ropa- que necesitan para llevar una vida razonable están viviendo en la pobreza. A pesar de que podríamos estar en desacuerdo sobre el umbral preciso (¿se puede vivir realmente, de manera razonable, en 2009, con 3.28 dólares por día, 1198 dólares por año? ¿Se puede incluso sobrevivir con la mitad de eso?), no parece haber nada malo en el concepto.

Sin embargo, hay problemas con este concepto de pobreza como privación absoluta. En primer lugar, está la cuestión de si es posible o no que una medida de ingresos realmente pueda captar lo que entendemos por personas que viven en una situación "no razonable" de carencias; no todas las cosas que permiten llevar una vida razonable pueden traducirse fácilmente en mercancías comprables. Luego está la cuestión de lo que entendemos por privación -¿de dónde viene nuestra idea de lo que la gente necesita?

\footnotetext{
${ }^{1}$ Véase Sutcliffe (2005:14), así como Banco Mundial, "Medición de la Pobreza a Nivel Mundial", disponible en: <http://web.worldbank.org/WEBSITE/EXTERnAL/TOPICS/EXTPOVERTY/ 0, contentMDK:20153855 menuPK:373757 pagePK:148956 piPK:216618 theSitePK:336992,00. html y Las Metas de Desarrollo del Milenio, disponible en: <http://www.un.org/millenniumgoals>.
} 
El propósito aquí es, en primer lugar, examinar las diferentes maneras en que podemos definir la pobreza. Se argumentará (sección II) que lo que la gente en general entiende por pobreza -O, más generalmente, por bienestar económico- no puede ser adecuadamente cubierto por una única medida absoluta. En particular, el significado no puede ser adecuadamente cubierto por el nivel absoluto de ingresos de una persona o de un pueblo. Esto ha sido ampliamente reconocido y se encarna en el Índice de Desarrollo Humano de las Naciones Unidas (IDH), en el concepto de capacidades de Sen, y en cierto grado en las propias MDM. El hecho de que haya varios fines en las MDM pone de relieve el reconocimiento de que alcanzar un objetivo de un cierto nivel de ingresos, por sí mismo, no eliminará la pobreza. Un tema estrechamente relacionado que se analiza en esta sección es que la pobreza (o el bienestar), no puede ser captada adecuadamente por una sola medida o con una combinación de medidas individuales, como el IDH.

Sin embargo, otra preocupación que desafía todos estos conceptos de pobreza y bienestar económico se discute en la sección III. Ninguno toma en cuenta las cuestiones de la desigualdad en la distribución del ingreso o la distribución según otras medidas de bienestar. El no incorporar, siquiera, una consideración de la distribución en el proceso de definir la pobreza (o, más en general, el bienestar económico) es conceptualmente problemático, si es que no es simplemente erróneo. Aunque esta cuestión conceptual ha sido ampliamente reconocida, sus implicaciones no han sido adecuadamente consideradas.

Tal vez lo más importante es que el no considerar la distribución genera graves problemas prácticos en las campañas contra la pobreza; en el mejor de los casos, al limitar su impacto y en el peor, condenándolas al fracaso (sección IV). Si la pobreza se entiende en términos absolutos, sin tener en cuenta las cuestiones de distribución, las estructuras sociales que generan la pobreza tienden a ser ignoradas. La política económica se considera entonces una cuestión técnica y se centra a menudo en programas particulares que se dirigen a ayudar a los pobres a mejorar su situación absoluta: nuevas variedades de semillas para aumentar los ingresos, los mosquiteros tratados con insecticida para mejorar la salud, más escuelas para elevar el nivel de educa- 
ción. Este tipo de políticas, cuando en realidad son aplicadas correctamente, puede tener efectos positivos (aunque a veces - por ejemplo, la introducción de nuevas variedades de semillas- puede tener efectos contradictorios). Sin embargo, deja sin resolver y sin examinar las estructuras sociales, las relaciones de poder, que han generado y siguen generando pobreza.

En gran medida, los pobres son pobres porque no tienen poder, y no tienen poder porque son pobres. Cuando se considera el poder, el foco de la política económica muda hacia cuestiones como la reforma agraria y el control efectivo de las acciones del Estado, es decir, de los factores subyacentes que determinan el gasto en salud, educación y otros servicios sociales. El problema de la pobreza, entonces, se plantea como un problema sociopolítico, no simplemente como un problema técnico. Los cambios técnicos pueden producir cambios en las relaciones socio-políticas, y esa es una de las razones, además de sus repercusiones directas, por la que a menudo son buenos esos cambios. Sin embargo, las soluciones técnicas tienen menos probabilidades de ser eficaces, cuando se aplican sin tener en cuenta las relaciones de poder - de lo que se hablará más en la sección IV).

El debate sobre el significado de la pobreza no es nuevo. El problema de averiguar qué hace que las personas estén bien o mal ha sido examinado por economistas y filósofos, desde Adam Smith a Karl Marx hasta John Rawls, Amartya Sen y muchos otros. Gran parte de esta discusión es muy útil, y tendremos ocasión de apoyarnos en ella. El objetivo principal es conectar estas cuestiones con la fase actual de las campañas para eliminar, o al menos reducir, la pobreza, y con las políticas particulares que surgen en estos esfuerzos. Gran parte de lo que se dirá es una crítica del programa MDM de las Naciones Unidas. Al mismo tiempo, sin embargo, se espera hacer alguna contribución a este debate continuo.

\section{LA POBREZA COMO UN CONCEPTO MULTIDIMENSIONAL}

Comúnmente medimos el bienestar económico de las personas, por sus ingresos o la riqueza material. Una persona es pobre o rica, en el lenguaje común, porque él o ella tiene un ingreso alto o bajo, o una cantidad grande 
o pequeña de riqueza material. Todo se reduce a una cantidad de dinero. Sin embargo, aunque a veces haya una fijación en el dinero, por lo general se reconoce que el dinero no es en sí el que determina el bienestar de uno. El dinero es la medida de las cosas que puede comprar, los productos que vemos como los determinantes de nuestro bienestar. En la medida en que es verdad que el bienestar de la gente está determinado-o casi determinado-por los productos básicos, bienes y servicios disponibles en el mercado, esto no es insensato.

En realidad hay importantes componentes de lo que determina el bienestar de las personas que no son bienes y servicios disponibles en el mercado. Por otra parte, los bienes y servicios, estén o no estén disponibles en el mercado, son ellos mismos - como el dinero- más precisamente vistos como un medio para algo más, algo que determina el bienestar de las personas. En un pasaje muy citado de La Riqueza de las Naciones, por ejemplo, Adam Smith escribe acerca de la pobreza en términos de la capacidad de una persona para aparecer en público sin vergüenza, y, en su tiempo, hacer esto habría dependido de ser el dueño de una camisa de lino: “[...] en los tiempos actuales, en la mayor parte de Europa, un trabajador se avergonzaría de aparecer en público sin una camisa de lino, cuya falta se supone que denota el grado vergonzoso de pobreza en el que, se presume, nadie puede caer sin una mala conducta extrema." "No es la camisa de lino por sí misma la que define la pobreza, sino la ausencia de la capacidad de aparecer en público sin vergüenza.

El concepto de capacidades (capabilities) de bienestar económico ha sido establecido por Amartya Sen. Él argumenta que "[...] el enfoque adecuado para evaluar el nivel de vida [...] es algo que puede llamarse la capacidad de una persona $[. .$. Es la] capacidad de funcionar [...] que más se acerca a la noción de calidad de vida" (Sen 1983:160). ${ }^{3}$ La capacidad general para funcionar en la sociedad implica, además de la capacidad de Smith para “aparecer

\footnotetext{
${ }^{2}$ Smith (1937 [1776], libro quinto, capítulo II, artículo IV: 822).

${ }^{3}$ Sen ha desarrollado ampliamente este concepto en varios lugares. Véanse, por ejemplo, Sen (1983, 1987 y 1992).
} 
en público sin vergüenza”, las capacidades más básicas, por ejemplo, para satisfacer las necesidades nutricionales, para escapar de las enfermedades evitables, para ser protegido, para ser vestido, para poder viajar y ser educado (Sen 1983:162-163).

Para el individuo, muchas de estas capacidades se pueden satisfacer con dinero. Los requerimientos de nutrientes, por ejemplo, casi siempre se pueden satisfacer si el individuo tiene suficiente dinero. En su conocido estudio de las hambrunas, Sen señala que el hambre en general no surge porque una sociedad tiene una absoluta falta de alimentos, sino porque la gente, o algunas personas, no tienen los derechos que les permiten obtener alimentos. (Sen 1981) Un derecho básico es el dinero con el que se puede comprar alimentos.

La satisfacción de otras capacidades, sin embargo, no puede ser completamente alcanzada a través del mercado. En un grado considerable, la capacidad del individuo para evitar la enfermedad depende de un amplio conjunto de condiciones sociales y de los bienes públicos (por ejemplo, los programas de vacunación y el aire limpio). La capacidad de llegar a ser educado también depende en gran medida de elementos fuera del mercado, aunque ciertamente hay aspectos de la educación que se pueden comprar como mercancía. Y la capacidad de viajar, por lo general, depende en gran medida de la existencia de bienes públicos - carreteras y puertos.

Más aún, incluso si los productos adquiribles establecen las capacidades de una persona, para diferentes personas diferentes cantidades (y tipos) de los productos básicos son necesarios para establecer las mismas capacidades. El ejemplo más evidente, al que Sen da énfasis, es la diferencia entre una persona que tiene una discapacidad física importante y una persona que no tiene esa discapacidad. La primera -por ejemplo, una persona que es incapaz de caminar- requiere más y diferentes productos para obtener la capacidad de viajar. Del mismo modo, la capacidad de satisfacer las propias necesidades nutricionales requiere de más mercancías para una persona muy grande que para una persona muy pequeña. Así que la misma cantidad de dinero no proporciona el mismo grado de bienestar para estas dos personas. 
El enfoque de capacidades de Sen respecto del bienestar y la pobreza, ha tenido un impacto muy grande y positivo al colocar la medición, el análisis y las políticas relacionadas con el bienestar material sobre una base más completa y realista. Afectó, en particular, la formación del Índice de Desarrollo Humano de la Organización de las Naciones Unidas (ONU) y las Metas de Desarrollo del Milenio -las cuales se discutirán en breve-. Hay, sin embargo, una base para la confusión en el enfoque de Sen. Por una parte, él desarrolló el concepto con referencia a las capacidades de los individuos -como lo ilustra el ejemplo sobre las personas con discapacidades físicas-. Por otro lado, el concepto ha sido ampliamente empleado en relación con sociedades enteras. A menos que creamos que dos sociedades tengan intrínsecamente, por ejemplo, personas de muy diferentes tamaños o proporciones muy diferentes de personas con discapacidad física, un ingreso nacional (o riqueza) semejante en ambas sociedades debe conducir a capacidades similares -al menos con respecto a estas capacidades que pueden ser atendidas a través del mercado-. Incluso con las capacidades que requieren grandes componentes que no son del mercado - la salud y la educación-, la capacidad general de las sociedades para asegurar las capacidades individuales de su gente debe tener una estrecha relación con el monto de ingresos (o de riqueza) en las dos sociedades. Si dos sociedades con el mismo nivel de ingresos (y la riqueza) son muy diferentes en términos de las capacidades individuales, no es porque las dos sociedades tengan diferentes capacidades en general.

Es ampliamente reconocido que el bienestar material no puede ser identificado sólo con el ingreso -sea examinando el ingreso de un individuo o el de una sociedad-. Sin embargo, una gran cantidad de análisis y política sigue basándose en el enfoque unidimensional del ingreso, y el desarrollo económico es visto en términos de crecimiento económico (es decir, en un aumento en el nivel de ingresos). Cuando la pobreza es el foco del análisis, por lo general, la medida es simplemente el nivel de ingresos de los pobres. Las instituciones financieras internacionales, en particular, continúan en gran medida en esta ruta unidimensional. El trabajo que ha surgido a través de las Naciones Unidas, sin embargo, ha tendido a basarse en una comprensión más multidimensional del bienestar material. 
Con el Informe sobre Desarrollo Humano 1990, el Programa de las Naciones Unidas para el Desarrollo (PNUD) presentó el Índice de Desarrollo Humano (IDH) junto con la lógica del índice. Parte de la lógica era que:

[...] La gente a menudo valora logros que no se expresan en lo absoluto, o no de inmediato, en mayores ingresos o en las cifras de crecimiento: una mejor nutrición y servicios de salud, un mayor acceso a los conocimientos, medios de vida más seguros, mejores condiciones de trabajo, la seguridad contra la delincuencia y la violencia física, horas de ocio satisfactorio, y un sentido de participación en la vida económica, cultural y política de sus comunidades. Por supuesto, la gente también desea mayores ingresos como una de sus opciones. Pero el ingreso no es el todo de la vida humana (PNUD 1990:9).

Los autores del Informe pasan a explicar el IDH, una medida parcial de este estándar de bienestar material más amplio -más vasto respecto a la medida tradicional por la vía de los ingresos-. El IDH es parcial, ya que es un índice basado en tres consideraciones: ingresos, salud y escolaridad/alfabetización. ${ }^{4} \mathrm{El}$ índice se basa en estos tres componentes, debido en parte a las limitaciones de los datos. La garantía de acceso a los medios de vida, las condiciones de trabajo y otros factores importantes mencionados en la cita anterior son difíciles de medir, y encontrar datos comparables internacionalmente sería prácticamente imposible. Además, si bien el significado de un índice de tres variables es bastante difícil de explicar (si es que se puede explicar en absoluto), un índice de muchas más variables perdería sentido completamente.

El surgimiento del IDH como una medida del bienestar de los países -O de la falta de éste- fue un acontecimiento importante y favorable. Fue un

\footnotetext{
${ }^{4}$ Uso el término escolarización y alfabetización en vez de educación o conocimiento -los términos más comúnmente usados para describir estas cuestiones- porque creo que esta es una descripción más precisa de lo que se incluye en la construcción del IDH (véase PNUD 2006:394). Este componente del IDH es una medida de las tasas de matrícula y las tasas de alfabetización, no de la educación o el conocimiento, que son conceptos mucho más amplios. De hecho, existe una confusión generalizada sobre esta cuestión en la economía del desarrollo, ya que lo que la gente suele querer decir con 'educación' es, de hecho, 'la escolaridad', es decir, un tipo particular de la educación que imparte una clase particular de conocimiento. Al confundir los dos, se implica que las personas que no tienen escolaridad formal no tienen educación y conocimiento, una idea muy engañosa.
} 
paso en general respetado y aceptado para lograr una medida más realista de la situación material de las personas y, al mismo tiempo, representaba y superaba un amplio descontento con el enfoque unidimensional tradicional relativo al ingreso.

Como una medida sumaria, univariable, del bienestar económico, el IDH tiene un considerable atractivo popular y político (véase, por ejemplo, Pant 1999). Sin embargo, los complejos fenómenos socio-económicos, son rara vez descritos con exactitud por una medida de tal tipo. En particular, no hay justificación para que los tres componentes del IDH tengan asignada la misma ponderación -O, para el caso, de las ponderaciones 2 a 1 asignadas a los dos componentes de la escolaridad/índice de alfabetización-. ¿Por qué, por ejemplo, pensaríamos que el efecto de un aumento de uno por ciento en el logaritmo de los ingresos debe ser igual en valor a un aumento de uno por ciento en el promedio de vida? y ¿por qué este impacto tiene que ser el mismo en todos los niveles? (véase McGillivray 1991 y Cahill 2005). Estos problemas formales en la creación de un índice de bienestar económico no son simplemente técnicos, sino que reflejan los problemas reales -tal vez la imposibilidad-de describir y evaluar una situación compleja con una sola variable.

La formulación de las Metas de Desarrollo del Milenio parece haber incorporado un reconocimiento del hecho de que el bienestar material no puede ser descrito por una sola variable. Sin embargo, implícitamente, las MDM aceptan la idea de que la pobreza se define en términos de ingresos. El primer objetivo de las MDM es "erradicar la pobreza extrema y el hambre", mientras que en la parte de la pobreza el objetivo es "reducir a la mitad la proporción de personas que viven con menos de un dólar al día". La multiplicidad de objetivos en las MDM - en materia de educación, la igualdad de género, mortalidad infantil y otras medidas de salud, la sustentabilidad del medio ambiente, y "una asociación mundial para el desarrollo"- parecen componentes del desarrollo, pero no son medidas de la pobreza. Esta distinción puede parecer un remilgo semántico, pero pone de relieve la continua falta de claridad sobre las cuestiones conceptuales que están en la base de las estrategias económicas en y para zonas de bajos ingresos del mundo. 
Sin embargo, el hecho de que las MDM incluyen un conjunto de metas que no se refieren simplemente a los ingresos, es un paso importante y positivo para alejarse del foco tenaz en los ingresos.

\section{LA POBREZA COMO UN CONCEPTO RELATIVO}

El problema con las MDM, como ocurre con el IDH y muchas otras conceptualizaciones de la pobreza, es que ignoran -o prácticamente ignoran- los problemas de distribución del ingreso. ${ }^{5}$ La definición de un dólar al día para la extrema pobreza es, como se acaba de señalar, una base principal de las MDM, y el componente de ingresos del IDH incluye sólo el nivel de ingresos per cápita de un país. Las MDM incluyen la promoción de la igualdad de género y el empoderamiento de las mujeres, y el PNUD ha comenzado a calcular y publicar, junto con el IDH, un índice de desarrollo de género. Pero, siendo como es tan importante y valioso el foco en la igualdad de género, no es lo mismo que un examen general de las cuestiones de la desigualdad y no altera nuestra comprensión de la pobreza. ${ }^{6}$

La pobreza absoluta, sea cual sea la definición precisa que se utilice, está muy extendida en el mundo, y crear las condiciones para que las personas se muevan $-\mathrm{O}$, mejor aún, las condiciones que les permitan trasladarse por sí mismas- de menos de un dólar o dos dólares al día a un nivel material superior, es extremadamente deseable. Al examinar la disputa sobre cómo definir la pobreza, si concepto absoluto o relativo es más significativo, Sen (1983:159) afirma: "Hay, yo diría, un núcleo absolutista irreductible en la idea de la pobreza. Uno de los elementos de ese núcleo absolutista es bastante obvio, aunque la literatura moderna sobre el tema a menudo hace lo posible

\footnotetext{
${ }^{5}$ Stanton (2006) presenta un nuevo cálculo del IDH basado en la consideración de la distribución del ingreso, la salud, la escolarización y la alfabetización. Es un ejercicio muy útil y demuestra cómo los rangos cambian cuando la distribución se toma en cuenta.

${ }^{6}$ De hecho, no sólo es matemáticamente posible la mejora en la igualdad de género (medida, por ejemplo, mediante la brecha salarial entre hombres y mujeres), mientras que la distribución global del ingreso se vuelve más desigual, sino que esto es precisamente lo que ha sucedido en Estados Unidos, y en otros países, en las últimas décadas.
} 
para ignorarlo. Si hay inanición y hambre, entonces - no importa lo que aparezca en términos relativos- está claro que hay pobreza. En este sentido, el cuadro -si procede- tiene que tomar asiento detrás de la consideración absolutista posiblemente dominante". Sin embargo, un enfoque exclusivo en la pobreza absoluta, que omite la consideración directa y explícita de la distribución del ingreso, tiene problemas. En efecto, es muy engañoso definir la pobreza, simplemente por el estándar absoluto.

La pobreza es un fenómeno contingente y construido socialmente, y el significado del término varía según las sociedades y con el tiempo. Esta contingencia está implícita en el estándar de las definiciones formales de la palabra. Consideremos, por ejemplo, la definición ofrecida en el diccionario Merriam-Webster Online: "La pobreza: 1a: el estado de una persona que carece de una cantidad de dinero o bienes materiales normal o socialmente aceptable" (véase, <http://www.m-w.com>). El término clave aquí es "socialmente aceptable". ¿Qué es lo que determina lo socialmente aceptable? Es decir, qué es lo que determina nuestro estándar para definir la pobreza? Una norma es necesaria para definir la pobreza, y la norma, una vez que vamos más allá de la inanición y el hambre, es por necesidad relativa.

El enunciado de Adam Smith, citado anteriormente, en relación con la vergüenza de una persona por aparecer en público sin una camisa de lino, reconoce el aspecto relativo del concepto de pobreza. La norma camisa de lino refleja las condiciones de bienestar material en Europa durante la época de Smith, pero en otras ocasiones y otros lugares la norma sería diferente.

En el otro extremo del espectro ideológico, Karl Marx expresó la misma idea básica. En su ensayo de 1847, Trabajo asalariado y capital, discutiendo cómo determinamos el bienestar económico de la gente, escribe: "Una casa puede ser grande o pequeña; en tanto las casas circundantes sean igualmente pequeñas, satisface todas las demandas sociales de una vivienda. Pero si surge un palacio al lado de la casita, la casita se reduce a una choza [...] Nuestras necesidades y placeres surgen de la sociedad; los medimos, por lo tanto, por la sociedad y no por los objetos de su satisfacción. Debido a que son de carácter social, son de naturaleza relativa" (sin fecha, [1847]:268-269). 
Una declaración similar, si bien más contemporánea sobre la cuestión, es la del antropólogo Sahlins (1974:37): “Los pueblos más primitivos del mundo tienen pocas posesiones, pero no son pobres. La pobreza no es una determinada cantidad de mercancías, ni es sólo una relación entre medios y fines; sobre todo es una relación entre las personas. La pobreza es una condición social". La declaración de Sahlins conlleva la implicación radical que la 'pobreza absoluta', absoluta en términos de la falta de bienes y servicios, realmente no tiene sentido. Las personas más primitivas del mundo-Sahlins parece tener en mente a los bosquimanos del Kalahari o los esquimales de Alaska (presumiblemente de una época anterior) - sin duda no tienen más bienes y servicios que los grupos del decil de ingresos más bajos en prácticamente todos los países de la actualidad. Asimismo, en términos de escolaridad y la atención sanitaria, estos pueblos no están mejor que los grupos más desposeídos en los países en la actualidad. Sin embargo, según la tesis de Sahlins, en el contexto de sus propias sociedades no son pobres. En sociedades primitivas, relativamente igualitarias, la pobreza es inexistente. Es sólo cuando se incorpora a estos pueblos (conceptual, si no prácticamente) en una sociedad más amplia, nacional o mundial, que caen en la pobreza.

El examen de la experiencia histórica de casi todos los países de altos ingresos subraya aún más el significado contingente -o familiar- de la pobreza. En Estados Unidos, por ejemplo, al final del siglo XVIII cuando el país se hizo independiente, según estimaciones actuales, el producto nacional bruto (PNB) per cápita era de 750 dólares a precios de 1990, muy cerca de 2 dólares por día (Atack y Passell 1994, cuadro 1.2). Sin embargo, nadie ve a la sociedad estadounidense de esa época como si en ella la pobreza hubiera sido masiva, como la cifra de un ingreso diario de 2 dólares por día implicaría. Ciertamente hubo personas que vivían en la pobreza en ese momento en Estados Unidos, pero la pobreza estaba determinada por las normas de la época; su posición con respecto a otros -los grupos de ingresos medios o tal vez los ricos- era la que definía la pobreza. El ejemplo expresa que no hay pobres, a menos que también haya ricos, o que algunas personas son pobres sólo en la medida en que otros son ricos. 
Estas cuestiones han sido reconocidas por Sen (1983), pero de una manera que distingue entre pobreza en términos de capacidades y la pobreza en términos de recursos. Sen sostiene que la pobreza es un concepto absoluto, en términos de capacidades de las personas, pero al mismo tiempo en diferentes circunstancias sociales -sociedades diferentes- se requieren diferentes recursos mercancías para que las personas alcancen sus capacidades. Refiriéndose al ejemplo de Smith de la camisa de lino, Sen señala que la capacidad de aparecer en público sin vergüenza es una capacidad absoluta, pero los recursos necesarios para cumplir con esta capacidad son relativos, determinados por las normas de la sociedad en particular. "A riesgo de simplificar demasiado, me gustaría decir que la pobreza es una noción absoluta en el espacio de posibilidades, pero muy a menudo toma una forma relativa en el espacio de las mercancías [...]" (Sen 1983:161).

El fenómeno por el cual las necesidades de mercancías de la gente se determinan en un sentido relativo, dependiendo de la sociedad en que viven, es en parte psicológico. Como dice Marx, medimos nuestras necesidades por la sociedad, es decir, que percibimos nuestras necesidades por lo que vemos a nuestro alrededor, lo que otros tienen en nuestra sociedad, y qué ha sido socialmente determinado como la norma. Decir que son nuestras necesidades psicológicas no quiere decir que son menos reales. Una vez superadas el hambre y la inanición, el cómo la gente percibe sus necesidades (y cómo los otros perciben sus necesidades) es lo que define su posición, su pobreza, y sin duda su vergüenza. Lo psicológico -o lo psicosocial- no es menos real, simplemente porque no está obviamente conectado a una necesidad biológica, como lo está una ingesta calórica mínima.

Más aún, al cambiar las sociedades, al ocurrir el crecimiento económico, cambia todo tipo de necesidades. Por ejemplo, conforme aumenta el ingreso en la sociedad, el empleo tiende a moverse fuera y lejos de la casa, generando una necesidad de servicios de transporte. Como otro ejemplo afín lo muestra, el crecimiento económico está acompañado generalmente por el aumento de la participación de la mujer en la fuerza de trabajo remunerada, generando necesidades de servicios (o bienes de capital del hogar) para sustituir el trabajo realizado tradicionalmente en el hogar por las mujeres. Además, 
como la naturaleza del trabajo cambia la educación y la formación ya no puede tener lugar en y alrededor del hogar (como sucede en las sociedades agrícolas tradicionales), y así surge una necesidad de escolarización. Nuevos tipos de trabajo, asociados con la expansión económica también generan una necesidad de cambios en la dieta y en los estimulantes. Pomeranz (2000, capítulo 3) señala que durante los siglos XVIII y xIx, la intensidad del trabajo en Inglaterra aumentó considerablemente, proporcionando una base para la expansión económica, y esta mayor intensidad de trabajo creó la necesidad de aumentar las calorías, suministrada en gran medida por el azúcar y por toda una clase de estimulantes -té, café, tabaco y cacao.

Una vez se reconoce que las necesidades son determinadas socialmente, dependientes de las condiciones sociales y relativas a las normas de la sociedad en general, entonces el papel de la distribución del ingreso como un factor determinante de la pobreza entra en escena. La pobreza existe, como todos parecen aceptar, cuando la gente tiene necesidades no satisfechas. En dos sociedades en las que el ingreso absoluto del segmento inferior (por ejemplo el quintil inferior) es la misma, la pobreza será mayor en la sociedad donde la distribución del ingreso es más desigual, ya que el segmento inferior se alejará más de la norma y por lo tanto habrá más carencia de necesidades socialmente determinadas. El crecimiento económico en sí mismo tenderá a tener un impacto limitado en la pobreza cuando la desigualdad permanece sin cambio, ya que, en la medida en que los estándares de necesidades de la sociedad aumenten, junto con el nivel medio de ingresos, quienes estén en la base seguirán siendo quienes estén en mayor necesidad.

Por supuesto, las normas sociales o las normas por las que se determinan las necesidades de la gente rara vez son claras, y la forma en que son establecidas es compleja. Por ejemplo ¿son normas establecidas por lo que la persona o la familia media tienen? ¿O las normas son establecidas por lo que el grupo más rico puede obtener? ¿Existe un estándar para una sociedad o normas diferentes en los distintos niveles? ¿Las necesidades de los que se ubican en la media están determinadas por las de quienes están encima de ellos, mientras que las necesidades de las personas en la parte inferior están determinadas por lo que tienen los del centro? A los efectos de definir la 
pobreza, las necesidades son probablemente mejor entendidas en relación con lo que tienen los de en medio, y la gente está más en la pobreza a medida que se aleje de la mediana. Sin embargo, las normas, incluso las normas de la pobreza, probablemente son influidas por quienes están en la parte superior de la sociedad.

Aquí el énfasis en la conexión indisoluble entre la distribución del ingreso y la pobreza no es nuevo. Por una parte, en los países de ingreso alto el estándar para la definición de la pobreza a menudo ha sido relativo, conectado a la distribución del ingreso - por ejemplo, la definición de la pobreza como existente cuando el ingreso de una persona es menos de la mitad de la media. De hecho, los países de la Unión Europea utilizan 60\% del ingreso promedio para definir la línea de pobreza (véase European Social Statistics, Eurostat, 2000). El argumento en este caso, sin embargo, es que el mismo razonamiento que conduce a una definición relativa de la pobreza en los países de altos ingresos, una definición que incluye la distribución de los ingresos, se aplica también en países de bajos ingresos - dejando espacio para cualificaciones teniendo en cuenta las condiciones extremas de inanición y hambre.

Por otro lado, hay un creciente reconocimiento de la importancia del impacto de la distribución del ingreso en la pobreza en los países de bajos ingresos, incluso en el contexto de una definición de pobreza absoluta. Si el crecimiento económico va acompañado de la igualdad de la distribución del ingreso, la pobreza absoluta (medida por los 2 dólares por día) se reduce más que cuando el crecimiento ocurre sin la ecualización. Dado que el crecimiento económico no significa automáticamente una mayor igualdad de ingresos, hay preocupación por que la estructuración del crecimiento sea de manera tal que resulte más favorable a la reducción de la pobreza absoluta. Por ejemplo, Khan (2005), examinando la experiencia de un amplio conjunto de países de bajos ingresos y usando una medida absoluta de la pobreza, sostiene que el aumento del empleo es una base para la reducción de la pobreza, debido a su impacto sobre la distribución del ingreso. Si bien la expansión del empleo reduce la pobreza mediante el crecimiento económico, su impacto por la vía de cambios en la distribución de ingresos tiende a ser mayor. 
El argumento, sin embargo, se basa en una definición diferente de la pobreza y no sólo implica que el crecimiento sin una mayor igualdad será menos eficaz en la reducción de la pobreza, sino que el crecimiento sin una mayor igualdad no tenderá a reducir la pobreza o sólo tiene un impacto parcial sobre la reducción de la pobreza.

La pobreza absoluta es importante todavía. Lo que se argumenta aquí no es a favor simplemente de una definición de pobreza en términos relativos. Como se dijo en la sección anterior, con una sola variable rara vez se puede describir con precisión una situación socioeconómica compleja, y la pobreza sin duda entra en esta categoría. Si bien puede ser tentador simplificar nuestra comprensión de la pobreza mediante la adopción total de la definición absoluta o del enfoque relativo, sería erróneo hacerlo. Sin embargo, debido a que la discusión sobre la pobreza en los países de bajos ingresos está actualmente dominada por el enfoque absoluto, parece necesario hacer hincapié en el concepto relativo.

\section{DE LA POBREZA COMO DISTRIBUCIÓN:}

\section{LA CUESTIÓN PRÁCTICA}

Al dar énfasis al concepto relativo de la pobreza, también se está necesariamente haciendo hincapié en el examen de la distribución del ingreso (y la riqueza) en cualquier discusión sobre la pobreza. Si bien es posible prestar atención a la distribución del ingreso en el marco del concepto absoluto de la pobreza -como muchos analistas lo hacen-, el énfasis en el concepto relativo fuerza a traer a la palestra este tema en cualquier discusión sobre la práctica de las políticas que puedan reducir la pobreza. Una crítica de los aspectos del proyecto de Desarrollo del Milenio va a aclarar algunos de estos temas.

\section{Las MDM, el crecimiento económico y las trampas de la pobreza}

El enfoque de política económica del proyecto de Metas de Desarrollo del Milenio ha sido desarrollado en el Reporte Sachs, Invirtiendo en el Desarrollo: 
un plan práctico para conseguir las Metas de Desarrollo del Milenio (Proyecto del Milenio de las Naciones Unidas 2005). El proyecto MDM se basa en un concepto de pobreza absoluta como se señaló anteriormente, siendo el primero de los objetivos el de reducir, para 2015, a la mitad el número de personas que viven con menos de 1 dólar por día.

El Reporte Sachs, que define la pobreza como pobreza absoluta, se centra en el crecimiento económico. Si bien el crecimiento económico per se no es una de las MDM, el informe toma el crecimiento económico como la clave para la consecución de las MDM -los objetivos de reducción de la pobreza y varios otros objetivos-. El Reporte Sachs no supone simplemente que el crecimiento va a resolver automáticamente todos los problemas, es decir llevar a la consecución de los distintos objetivos; presta atención a los datos de crecimiento, especificando políticas orientadas hacia los diferentes objetivos. Sin embargo, el crecimiento económico es clave, y la atención a otros aspectos del progreso se inscribe en el marco del crecimiento. Cuestiones relativas a la distribución del ingreso - por no hablar de cuestiones relacionadas con el poder social y político- se ignoran. En todo el texto del Reporte Sachs no aparece el término ‘distribución del ingreso’ y en ninguna parte del Informe Diez. Recomendaciones clave hay ninguna referencia a la desigualdad o la igualdad, a excepción de la inclusión de la igualdad de género, junto con muchas otras cuestiones en las que las estrategias de reducción de la pobreza deben centrarse, por ejemplo, la productividad rural, salud, educación, entre otras. (Aunque en el informe se habla de 'empoderamiento', el término se utiliza para significar aumento del bienestar económico absoluto de la población. El aumento del bienestar económico de la población es algo bueno, pero no es lo mismo que el cambio en las relaciones sociales que constituyen el empoderamiento real. Esta cuestión se examina con más detalle más adelante.

El enfoque básico del Reporte Sachs sobre el crecimiento económico es argumentar que los pobres son pobres porque están atrapados en una trampa de la pobreza. Porque las personas y los países pobres tienen ingresos tan bajos que no pueden ahorrar e invertir lo suficiente para salir ellos mismos de la pobreza: "Ahora podemos ver la esencia de la trampa de la 
pobreza. Los países más pobres ahorran muy poco para lograr el crecimiento económico, y la ayuda es demasiado baja para compensar la baja tasa de ahorro interno" (p. 34). A raíz de este diagnóstico del problema y de la atención al crecimiento económico, la mayor parte del informe está dedicada a las cuestiones de cómo movilizar suficiente capital, para que las tasas de inversión puedan aumentar en los países de bajos ingresos. La respuesta es una combinación de mayores cantidades de ayuda extranjera, mayores cantidades de ahorro interno y de políticas macroeconómicas que inducirán "enormes inversiones nuevas" (p. 63).

El informe contiene numerosas recomendaciones particulares de política que son directamente relevantes para las condiciones de los pobres. Estos incluyen (capítulo 5), por ejemplo:

- Asegurar la universalización y finalización de la educación primaria a través de "[a]bolición de las cuotas escolares, e incentivos especiales para llevar a los grupos más marginados a la escuela" (p. 85), así como la construcción de nuevas escuelas y la contratación de más maestros.

- El aumento de la productividad alimentaria de los pequeños agricultores a través de una nueva revolución verde en África y en partes marginadas de América Latina y Asia, con la participación de inversiones privadas para mejorar la disponibilidad de agua y ampliar la infraestructura y ampliar el conocimiento y la disponibilidad de la tecnología más productiva.

- La creación de empleo en la manufactura mediante la expansión de la infraestructura urbana, apoyo a los programas de capacitación y un trato fiscal favorable para los inversionistas -sobre todo, al parecer, a los inversores extranjeros.

\section{Barreras para el cambio}

En general, estos son programas valiosos - aunque más adelante se discutirán los alegatos al respecto de un trato fiscal favorable para atraer la inversión extranjera. El problema radica, en primer lugar, en las explicaciones de porqué estos programas todavía no se han aplicado en gran parte del mundo de bajos ingresos. Básicamente, el informe dice que estos programas han faltado a causa de la trampa de la pobreza y por la ignorancia. La gente en los países pobres no ha tenido los fondos para llevar a cabo los programas 
necesarios, y han sido ignorantes - los funcionarios del gobierno, las empresas y los pobres- respecto de las políticas adecuadas y las tecnologías que se necesitan. En cuanto a la supuesta ignorancia de los funcionarios del gobierno, por ejemplo: "[la ...] razón por la que algunas de las metas [de Desarrollo del Milenio] no se están alcanzando, es simplemente porque los políticos no son conscientes de los desafíos, no saben qué hacer, o por negligencia respecto de cuestiones públicas esenciales" (p. 45). Respecto de la ignorancia de los directores de empresa y de los propios pobres, el informe está lleno de invocaciones para difundir el conocimiento, casi como si esto fuera la panacea para la pobreza.

La difusión del conocimiento es una cosa buena. Pero la falta de conocimiento en sí rara vez es la barrera fundamental para el progreso, y, cuando falta el conocimiento, el problema tiene raíces que no son abordadas por el informe. El informe parece explicar la falta de conocimiento por una combinación de una falta de comprensión de la importancia de los conocimientos y la falta de fondos para apoyar la difusión del conocimiento. Sería más útil reconocer que el conocimiento está ligado con el poder y la riqueza.

Consideremos, por ejemplo, la cuestión de la ampliación de la escolaridad en los países de bajos ingresos. India, a pesar de su impresionante crecimiento económico en los últimos años y la tan cacareada fuerza de trabajo altamente educada que ha desempeñado un papel importante en ese crecimiento, sigue teniendo un record relativamente pobre en la educación básica. En 2004, la alfabetización entre las mujeres mayores de 15 años fue de $47.8 \%$ y de $73.5 \%$ para los hombres (PNUD 2006:373). Si bien hay muchos aspectos en una explicación de estas bajas tasas (y de la disparidad de género), el siguiente comentario de Drèze y Sen (1995:107) es ilustrativo:

[...] La democracia local a menudo ha sido socavada por la desigualdad social aguda. La poca participación de las mujeres en las instituciones representativas locales, tales como los panchayats, es un claro ejemplo de este problema. En grandes zonas [de la India], el gobierno local está en manos de los hombres de casta superior de las clases privilegiadas, que sólo débilmente rinden cuentas a la comunidad y a menudo terminan utilizando los servicios públicos locales como instrumentos de clientelismo. En algunos casos, la élite rural ha sido no sólo indiferente a la promoción general de los servicios públicos locales, sino incluso ha 
impedido su expansión para evitar el empoderamiento de los grupos desfavorecidos. En Utter Pradesh, por ejemplo, todavía es posible encontrar pueblos donde un poderoso terrateniente se ha opuesto activamente a la creación de una escuela del pueblo.

La situación de la India no es la única que muestra la conexión entre el poder social y el progreso - o la falta de progreso-de la escuela. Al examinar la situación del nordeste de Brasil en un documento perspicaz, titulado "El miedo a la educación”, Tendler (2002) resume sus conclusiones como sigue:

En la investigación realizada para este trabajo [...] los propietarios y gerentes de grandes empresas de manufactura moderna en la industria textil, del vestido, del calzado del noreste de Brasil reportaron que, para su agradable sorpresa, habían sido capaces de vivir con el analfabetismo sin comprometer su capacidad de competir. No apreciaban una fuerza de trabajo educada y, de hecho, a veces expresaban en voz alta "que la educación en exceso era algo malo". Este miedo a la educación también invade el pensamiento de los políticos y los gobiernos, particularmente de los departamentos que apoyan el desarrollo económico -y en particular a nivel subnacional, donde las decisiones de financiar y mejorar la educación se hacen a menudo-. Estos actores frecuentemente interpretan que la única ventaja comparativa de su región en el desarrollo económico es la originada en la mano de obra barata; se preocupan de que una fuerza laboral más educada puede disminuir esa ventaja, llevando a un aumento general de salarios relativos de la región, y reduciendo la apreciada docilidad y el agradecimiento de la fuerza de trabajo de la región; también esperaban perder la rentabilidad de su inversión en la mejora de la educación, a causa de la emigración de los mejores trabajadores. Las experiencias mencionadas anteriormente acerca de los propietarios de la empresa y los directivos, a su vez, parece que se traducen en una falta de presión sobre los gobiernos de importantes élites locales para mejorar la educación, una especie de fatal ausencia de presiones derivadas de la demanda. Estas percepciones distintas, es importante tener en cuenta, son eminentemente racionales, tanto en términos privados como económicos.

Más allá de estos casos particulares, diversos estudios han mostrado una relación general entre la desigualdad, especialmente en la propiedad de la tierra, y la débil expansión de la escolarización (Bowles 1978; Galor et al. 2004; Alesina y Rodrik 1994). El punto común de estos ejemplos y estudios de carácter más general es que tienden a demostrar que la falta de avances en la escolarización, en zonas de bajos ingresos del mundo no se explica por la falta de voluntad, la ignorancia acerca de los beneficios de la escolarización o incluso por la falta de fondos en sí. En cambio, la falta de progreso en la educación a menudo, si no siempre, se explica por el hecho de que los grupos 
de poder no tienen interés en avanzar en la escolarización de la población. Su interés puede ser directo (una fuerza laboral educada puede ser menos dócil) o indirecta (no vale la pena pagar una fuerza de trabajo educada) o puede funcionar en un nivel social más amplio (una población educada puede ser menos propensa a aceptar el status quo). No importa como sea visto, tal interés es real, y la capacidad de quienes tienen ese interés para imponerlo sobre la sociedad en general es el resultado de su poder socio-político y su situación económica, es decir se trata de un resultado de la desigual distribución del ingreso y la riqueza. En muchas sociedades, entonces, es difícil imaginar un progreso real en la educación sin algunos cambios en la estructura del poder y la distribución del ingreso y la riqueza.

\section{Impactos de la distribución del crecimiento}

En su llamamiento a aumentar "la productividad de los alimentos de los pequeños agricultores”, el Reporte Sachs vuelve a ver el problema en términos de ignorancia. Abogando por una nueva revolución verde en África y las regiones olvidadas de Asia y América Latina, el Reporte presenta la reducción de la pobreza y el desarrollo económico como algo posible de lograr a través de la solución técnica. Si bien, como se señaló anteriormente, las recomendaciones del informe no tienen en cuenta las cuestiones de distribución que crean barreras para el cambio, su enfoque sobre la solución técnica también oculta los impactos distributivos de sus programas preferidos -de su receta, en particular, para una nueva revolución verde.

El impacto distributivo de las anteriores revoluciones verdes es un tema de controversia. Por un lado, la mayor producción de granos consecuencia de semillas de alto rendimiento e insumos asociados, puede contribuir al crecimiento económico general; y la mayor disponibilidad y menores precios de alimentos básicos, mejorar la suerte de los pobres. Además, los pequeños agricultores pueden beneficiarse tanto como productores como consumidores. Por otra parte, la tecnología de la revolución verde tiende a estar sesgada hacia el incremento de los rendimientos de la tierra, y por lo tanto no puede haber una fuerte correlación entre el tamaño de las parcelas 
y la magnitud de los beneficios que obtienen los agricultores. Además, la eficacia de las semillas de alto rendimiento depende, en general, del acceso al agua y la compra de insumos -no sólo de las semillas mismas, sino también de los fertilizantes y plaguicidas-. El acceso a la compra de insumos y acceso al agua por lo general exige el acceso al crédito (para financiar sistemas de riego en el caso del agua), y los pequeños agricultores están en clara desventaja para obtener crédito. En muchas circunstancias, el acceso al agua depende directamente del poder político. Debido a que la tecnología a la vez mejora el rendimiento de la tierra como plantea la necesidad de crédito para los pequeños agricultores, puede exacerbar la falta de tierras.

Algunas experiencias sugieren que la revolución verde no sólo agudiza las desigualdades, en general, sino que tiene un impacto particularmente negativo en la desigualdad de género. Una adaptación de la Organización para Agricultura y la Alimentación (FAO, por sus siglas en inglés) del trabajo de Jiggins (1986) argumenta:

[...] A pesar de su éxito para aumentar la oferta agregada de alimentos la Revolución Verde, en cuanto enfoque de desarrollo, no se ha traducido necesariamente en beneficios para los estratos más bajos de la población rural pobre, en términos de una mayor seguridad alimentaria o mayor oportunidad económica y bienestar [... La ] introducción de variedades de alto rendimiento de arroz en Asia ha tenido un impacto importante sobre el trabajo de la mujer rural y el empleo, la mayor parte desfavorable, mediante el aumento de la necesidad de ingresos monetarios en los hogares rurales para cubrir los costos de los insumos tecnológicos, lo que ha obligado a las mujeres a trabajar en la agricultura, ha incrementado la necesidad de mano de obra femenina no remunerada para las tareas de la agricultura, aumentando así la carga de trabajo de la mujer, que ya era elevada; [y] eliminando, mediante la mecanización, oportunidades salariales para las mujeres.

En cuanto a la aplicación de los métodos de la revolución verde en África, el informe de la FAO continúa:

[Los intentos] para reproducir la Revolución Verde en África rara vez reconocieron la importancia de la actividad agrícola independiente de las mujeres y de actividades generadoras de ingresos para satisfacer las necesidades alimentarias de la familia, y de dinero efectivo para la compra de bienes vitales para el bienestar familiar [...] El hecho de no percibir y/o responder a la asignación diferenciada de recursos y responsabilidades entre hombres y mujeres en los hogares agrícolas, significó que las necesidades laborales de las mujeres 
para la producción de cultivos se incrementaran, aunque el control de los ingresos quedó en manos de los hombres. Por otra parte, a las mujeres se les asignaron pequeñas parcelas de tierras marginales para la producción de alimentos, lo que dio lugar a insuficientes alimentos para la familia y a una mayor presión sobre entornos frágiles. ${ }^{7}$

Una revisión de los análisis de los efectos distributivos de la revolución verde (Freebairn 1995) encontró que 80\% de ellos concluyó que la introducción de la tecnología sobre la base de variedades de alto rendimiento de grano dio como resultado una mayor desigualdad a nivel de los productores e interregional. El que la mayoría de estos estudios arribe a este resultado no hace que la conclusión general sea correcta, y el impacto distributivo de la tecnología sigue siendo controvertido. Pero la cuestión no puede ser vista como irrelevante, una conclusión que podría fácilmente deducirse del Reporte Sachs. Más aún, como la reseña de Freebairn sugiere, el impacto distributivo de la tecnología de la revolución verde depende, en gran parte, del marco general en el que se adopta -i.e. la naturaleza del marco institucional y social-. Es decir, el grado en que una solución técnica es probable que mejore las condiciones de los pobres depende, en gran medida, del contexto en el que se introduce - de la manera en que operen los mercados y de la forma en que se apliquen las políticas de gobierno, lo que depende, en gran parte, de la estructura previa de la distribución y el poder.

El cuadro en el que la revolución verde ha tenido impacto en muchas partes del mundo ha sido un contexto con grandes desigualdades en la distribución del ingreso y la riqueza; algo inmediatamente relevante es la distribución desigual de la tenencia de la tierra, lo que sirve para crear la pobreza y limitar los cambios, como se ha mencionado anteriormente. La larga historia de terratenientes, estructuras de latifundios-minifundios y la no tenencia de tierras rurales, que ha caracterizado la vida rural en muchas partes del mundo, ha generado desigualdad y pobreza generalizada (ya sea que se le defina en términos absolutos o relativos). Al mismo tiempo, el poder político de los

\footnotetext{
${ }^{7} \mathrm{El}$ informe de la FAO se encuentra disponible en < http://www.fao.org/FOCus/E/Women/green-e. htm > (consultado el 28 de septiembre 2007). Respecto del fracaso de los programas de desarrollo en el reconocimiento de los diferentes papeles de hombres y mujeres en la agricultura, véase Elson (1991).
} 
grandes terratenientes ha limitado el cambio: evitando programas sociales, bloqueando la reforma agraria, el control de agua y limitando avances en la productividad.

\section{Atrayendo inversión en el contexto de la globalización}

Una concentración en el crecimiento sin tener en cuenta la distribución del ingreso y las relaciones de poder se manifiesta también en la promoción, en el Reporte Sachs, de las ventajas fiscales como un medio para atraer la inversión en general y la inversión extranjera en particular. Como dice el Informe, la evidencia existente sugiere que las concesiones fiscales, cuando se combinan con políticas complementarias apropiadas, por ejemplo expansión de la infraestructura y la formación de recursos, atraen la inversión extranjera. La conexión entre la inversión extranjera y el crecimiento económico, sin embargo, es más compleja que lo que sugiere el informe, y el impacto de la inversión extranjera en la distribución del ingreso y, por lo tanto, en la reducción de la pobreza, es al menos, un tema polémico.

El argumento de la trampa de la pobreza del informe es esencialmente un argumento del lado la oferta, ya que explica la falta de inversión en países de bajos ingresos como resultado de una oferta insuficiente de capital. Este razonamiento -compartido por muchos políticos y economistas-conduce a la proposición de que el crecimiento se verá reforzado por la inversión extranjera. En la medida, sin embargo, que el crecimiento es limitado en el lado de la demanda -es decir, por las oportunidades de inversión- la inversión extranjera puede tener el efecto de desplazar los fondos de origen interno. Un ejemplo de este fenómeno lo proporciona México, donde en 1980 el acervo de inversión extranjera directa (IED) fue de sólo 3.6\% del producto interno bruto (PIB); se elevó a $8.5 \%$ en 1990 , a $16.7 \%$ en 2000 y a $26.5 \%$ en 2003 (Conferencia de las Naciones Unidas sobre Comercio y Desarrollo, UNCTAD, por sus siglas en inglés; UNCTAD, 2004:405). Sin embargo, a lo largo de estos años de creciente IED, la inversión bruta con relación al PIB fue menor que lo había sido en la década de 1970 y principios de 1980 (Mattar et al. 2002), y el crecimiento económico fue relativamente lento (incluso después 
de la crisis financiera de 1994). Si bien la situación de México no puede ser típica, por lo menos los impactos de la IED en el crecimiento económico son mucho más variados y complejos de lo que sugiere el informe (véase, por ejemplo, De Mello 1997).

Aun cuando la inversión extranjera induzca un crecimiento económico más rápido su impacto en la distribución del ingreso puede ser negativo. ${ }^{8}$ Los estudios que examinan la relación entre la IED y la desigualdad frecuentemente se centran en la desigualdad salarial que se genera por la entrada de empresas extranjeras en los países de bajos ingresos. Por ejemplo, te Velde (2003:4-5), centrándose en América Latina, concluye:

[...] No todos los tipos de trabajadores necesariamente ganan en la misma medida con el aumento de la IED. Las razones de esto incluyen: la IED induce el cambio tecnológico específico en destrezas [...] y proporciona un mayor adiestramiento al personal capacitado que a los trabajadores no calificados. Una revisión de la evidencia micro y macro muestra que, como mínimo, es probable que la IED perpetúe las desigualdades [...] La nueva evidencia empírica muestra que la IED no tuvo un efecto de reducción de la desigualdad en América Latina [...] En países como Bolivia y Chile, la IED puede haber incrementado la desigualdad salarial. Si bien esto no implica que la IED fue buena o no para el desarrollo y la reducción de la pobreza en estos países, esto implica que la mayor parte de los beneficios de la IED se han concentrado en los trabajadores calificados y educados.

Tan importante como parezca ser la desigualdad de los salarios asociados a la inversión extranjera, hay un problema adicional que acontece cuando la inversión es atraída por ventajas fiscales. El enfoque de las ventajas fiscales

\footnotetext{
${ }^{8}$ Para una reseña de la cuestión y las evidencias, véase Tsai (1995:480), quien concluye: “[...] dos características principales surgen de nuestros análisis. En primer lugar, la correlación parcial entre los acervos de IED y la desigualdad, estimada utilizando el modelo básico, es extremadamente sensible a la inclusión de variables ficticias geográficas. Esto implica que la correlación estadísticamente significativa entre la IED y la desigualdad de ingresos, ampliamente obtenida en estudios anteriores, puede capturar más bien las diferencias geográficas en la desigualdad de la influencia deletérea de la IED. En segundo lugar, en la medida en que la IED da lugar a una distribución más desigual de los ingresos en los países huéspedes menos desarrollados, sólo los países menos desarrollados (PMD) del Este/Sureste asiáticos parecen ser los realmente perjudicados por la afluencia de IED durante el período considerado. Tenemos que reiterar, sin embargo, que la declaración anterior se refiere al impacto marginal solamente. [...] Pero, incluso en el sentido marginal nuestros resultados tienden a apoyar los argumentos de los teóricos de la dependencia $[\ldots]$.
} 
para atraer inversión coloca a las empresas en una fuerte posición de negociación a partir de la cual pueden hacer que los gobiernos de diferentes países se enfrenten entre sí. Además, el tipo de inversión que es sensible a las tasas de impuestos es a menudo muy móvil -la elaboración de prendas de vestir es un buen ejemplo- y esa movilidad aumenta el poder de negociación de las empresas, una vez que la práctica de competir a partir de ventajas fiscales se ha iniciado. Al examinar la cuestión de las reformas estructurales en América Latina y su impacto en la distribución del ingreso, Morley (2000:29) escribe:

[...] en un mundo de perfecta movilidad del capital, los países se verán obligados a competir ofreciendo generosas ventajas fiscales, créditos subvencionados y otras costosas formas de asistencia para atraer capital extranjero. Pero no es sólo el capital extranjero el que se ve afectado. El mismo argumento es válido para el capital nacional. Tanto el gobierno como el trabajo, se verán obligados a aceptar acuerdos que sean lo suficientemente generosos para garantizar que los empresarios nacionales y los titulares de la riqueza se contenten con dejar su dinero invertido en su país de origen. De esta manera, la apertura de la cuenta de capital desplaza el equilibrio de poder en favor de los titulares del capital.

Si bien la principal preocupación de Morley son las consecuencias de la liberalización de los mercados de capital, sus observaciones destacan los problemas de distribución y poder que pueden estar asociados con los esfuerzos para atraer -y retener- capital sobre la base de la competencia por la vía de las concesiones fiscales. ${ }^{9}$

El enfoque de las ventajas fiscales para inducir la inversión percibe el crecimiento económico como algo necesariamente basado en los fines de lucro. Para aumentar los ingresos en general, de acuerdo con este concepto, es necesario aumentar los ingresos de capital en primer lugar. Incluso si tiene éxito el aumentar los ingresos, la distribución del ingreso probablemente se volverá más desigual. Es un enfoque que se basa en la aceptación y la mejora

\footnotetext{
${ }^{9}$ Beer y Boswell (2002) expresan conclusiones similares, que también se centran en la forma en que las relaciones de poder se ven afectados por la globalización. Ellos llegan a la siguiente conclusión (p. 51): "La investigación presentada aquí muestra un cambio en las relaciones capital/trabajo provocados por la globalización que han contribuido significativamente al aumento de la desigualdad de ingresos a lo largo del mundo."
} 
del poder del capital, especialmente el capital extranjero. El crecimiento basado en el lucro puede o no producir un crecimiento más rápido, pero casi necesariamente garantiza un crecimiento más desigual.

La experiencia de décadas recientes, no sugiere que el crecimiento económico se refuerza efectivamente atrayendo capital extranjero. Por ejemplo, en la década de 1970 varios países de América Latina procuraron su desarrollo con una fuerte dependencia de la inversión extranjera, mediante la política fiscal y otros medios para atraer esa inversión. Brasil y México son excelentes ejemplos. En Asia oriental, al mismo tiempo, Taiwán y Corea del Sur, si bien aceptaron la inversión extranjera, limitaron y controlaron esta inversión. Las experiencias de crecimiento relativo de las dos regiones son bien conocidas. Además, aunque las diferencias en la distribución del ingreso entre las dos regiones pueden atribuirse a varios factores, el mayor grado de igualdad en los países de Asia oriental es también digno de mención. ${ }^{10}$

Como la referencia a la experiencia de Asia oriental debe mostrar, la inversión extranjera no es mala. El que la inversión extranjera tenga malos o buenos efectos depende, en gran medida, de cómo es atraída y controlada. Su impacto sobre el crecimiento económico y la distribución del ingreso en los países receptores depende de varios factores. Algunos de estos factores - por ejemplo, la importancia del apoyo a los programas de formación- son reconocidos en el Reporte Sachs. Sin embargo, cualquier enfoque de la inversión extranjera que no tome en cuenta la manera en que afecta a la distribución del ingreso y las relaciones de poder (por no hablar de las complicaciones en la forma en que afecta al crecimiento económico) conduce a un enfoque inadecuado para mitigar la pobreza.

\section{Alternativas $^{11}$}

El Reporte Sachs y el Proyecto de Metas de Desarrollo del Milenio son un avance importante respecto del enfoque del Consenso de Washington, que

\footnotetext{
${ }^{10} \mathrm{El}$ manejo de la inversión extranjera por Taiwán y Corea del Sur en este periodo está descrito, respectivamente, en Wade (1990) y Amsden (1989).

${ }^{11}$ Algunos de los temas de esta sección se desarrollan con más amplitud en MacEwan (1999).
} 
durante varios años dominó mucho del análisis y la política de desarrollo económico. El informe y el proyecto de las MDM son valiosos porque van más allá de una simple confianza en el mercado y una inclinación a poner énfasis en el crecimiento económico para resolver los problemas de la pobreza. Sin embargo, su incapacidad para abordar las cuestiones de los ingresos (y la riqueza), la distribución y el poder es una deficiencia grave que limita el grado en que la mitigación de la pobreza puede ser enfrentada efectivamente. Parte del problema radica en abordar la pobreza simplemente como una cuestión absoluta; si el aspecto distributivo de la pobreza fuera reconocido, estas cuestiones no podrían ser excluidas de la discusión. Hay alternativas, distintas maneras en que las cuestiones de distribución y el poder pueden ser colocadas en primer plano en la política de reducción de la pobreza. En la base de las políticas alternativas está un enfoque fundamentalmente diferente - distinto de aquel del Reporte Sachs- que es el de considerar el papel de los propios pobres. Como Banuri (2005:43) señala:

[...] El enfoque del informe [Sachs] no es el empoderamiento de los pobres ni la creación de conocimiento para ser puesto en manos de los pobres; más bien su atención se centra en hacer algo por los pobres. [El Informe esencialmente ignora un enfoque que] hace hincapié en invertir en el capital social de los pobres, en la movilización social, en la creación de la organización colectiva que permita que surja la toma de decisiones colectivas y el fortalecimiento de las comunidades y la acción comunitaria. Éste [permitiría] a los pobres hacerse cargo del proceso. Los defensores de este enfoque no cesan de recordarnos, no tratar a los pobres como un problema sino como personas.

Mucho se ha hablado del concepto de 'empoderamiento' - en el Reporte Sachs, en diversos documentos del Banco Mundial, y en muchas otras discusiones de la pobreza y el desarrollo económico-. Sin embargo, el empoderamiento se presenta generalmente en los términos económicos más estrechos como un proceso o producto de aumento de los ingresos de los pobres y la educación de los pobres (es decir, dar escolarización). 'Poder', sin embargo, es un concepto relativo. En la medida en que el ingreso es una base para el poder, el ingreso relativo es lo que importa. Si, por ejemplo, los ingresos del quintil inferior de la sociedad suben un diez por ciento mientras que 
los del resto de la sociedad también se incrementan en un diez por ciento, es difícil argumentar que el primero tiene más poder. Las personas en el quintil inferior pueden tener un poco más de flexibilidad en sus vidas, y esto parece darles un poco más de poder en sus relaciones con el resto de la sociedad. Sin embargo, los otros miembros de la sociedad también han ganado en flexibilidad. Sin ningún cambio en la distribución del ingreso es difícil ver cómo el sólo aumento de los ingresos puede conferir más poder a los pobres.

Además, el poder no es simplemente un producto de los ingresos (o de la riqueza). Depende de un conjunto de arreglos sociales y políticos -el capital social, la movilización social, la organización colectiva y la toma de decisiones y el fortalecimiento de las comunidades mencionadas por Banuri-. Hay programas que pudieran promover tales arreglos, programas que tienden a mejorar la distribución del ingreso y el poder en los países de bajos ingresos y con ello contribuir de manera significativa a la reducción de la pobreza.

Un buen ejemplo es la reforma agraria redistributiva, que podría servir de base tanto para la mejora de la distribución del ingreso como para el aumento de la productividad agrícola en muchas partes de bajos ingresos del mundo. La reforma agraria no sólo puede aliviar directamente la pobreza en el campo, sino que, como se ha señalado en el debate de la escolarización, el poder político de los grandes terratenientes es, a menudo, un obstáculo para el cambio en otros sectores de la sociedad. La reforma agraria no sólo podría cambiar la distribución de la riqueza y los ingresos, sino que puede alterar la distribución del poder político.

El impacto en la mejora de la igualdad, derivado de la reforma agraria redistributiva puede ser relativamente evidente, pero su función de mejora de la productividad no es tan ampliamente reconocida. Griffin et al. (2002:286), presentan el argumento de manera bastante efectiva. Señalan que:

La proporción relativamente baja de las tasas de interés respecto de los salarios que enfrentan los grandes terratenientes [en comparación con los pequeños propietarios] alienta a adoptar una mayor razón capital/trabajo en el cultivo, es decir, el uso de técnicas más mecanizadas 
[...] Del mismo modo, la proporción relativamente baja de las tasas de arrendamiento de tierras respecto a las tasas salariales que enfrentan los grandes terratenientes, les alienta a cultivar sus tierras ampliamente, es decir, a adoptar coeficientes más bajos de tierra-trabajo [...] En otras palabras, los pequeños agricultores cultivan la tierra con mayor intensidad y genera más empleo por unidad de tierra. Dado que el capital es escaso y la mano de obra abundante en las zonas rurales de los países en desarrollo, los métodos de cultivo utilizados por los pequeños agricultores se aproximan más a los métodos socialmente óptimos de capital y la tierra que los métodos intensivos normalmente adoptados por los grandes terratenientes [... tanto] la producción por unidad de tierra, o el rendimiento, a menudo es mayor en las pequeñas explotaciones que en las grandes. De hecho, hay una gran cantidad de evidencia empírica que muestra que el rendimiento varía inversamente con el tamaño de las explotaciones.

Griffin et al. también hacen dos observaciones adicionales especialmente importantes aquí. En primer lugar, los grandes terratenientes tienen, y tratan de mantener, una posición de monopsonio en relación con el mercado laboral, y por lo tanto tienden a abstenerse de vender tierras a los pequeños campesinos, incluso cuando parece que al hacerlo aumentarían sus beneficios. Sin embargo, están preocupados por el control social y obstruyen el acceso de los pequeños campesinos (y presumiblemente, de los campesinos sin tierra) a las alternativas con que el poder de los grandes terratenientes en el mercado de trabajo sería socavado.

En segundo lugar, Griffin et al. observan que una reforma agraria redistributiva no sólo provocaría la reducción de la pobreza en las zonas rurales, sino que también contribuiría a la reducción de la pobreza en las zonas urbanas: "La razón de esto es que el ingreso de los pobres rurales establece un piso para los salarios urbanos, ya que nadie va a migrar del campo a la ciudad como no sea que esperen estar al menos tan bien como antes de la migración. El aumento de los ingresos rurales por lo tanto, aumenta los salarios de reserva de los pobres urbanos y esto ayudará a reducir la pobreza urbana" (p. 292).

Griffin et al., reconocen los problemas políticos relacionados con una reforma agraria redistributiva. Los autores concluyen su artículo afirmando que, debido a la elevada proporción del precio de la tierra respecto del valor anual de la producción neta del suelo, la compra de la tierra de los grandes terratenientes, para redistribuirla, sería prohibitivamente costosa. Terminan 
con el comentario (p. 321): "La conclusión ineludible es que una importante reforma agraria redistributiva es imposible si la transferencia de tierras se basa en los precios del mercado libre; el gobierno debe actuar para disminuir los precios del suelo o debe haber una confiscación directa de algunos propietarios. Esta es una alternativa dolorosa, pero es inevitable si hay alguna esperanza de éxito”.

La reforma agraria y la reducción directa de la pobreza y el aumento directo de la producción que puede generar, no son simplemente fines en sí mismos. Como se ha mencionado, la reforma agraria implica también un cambio en el poder socio-político. Por otra parte, este cambio puede ser mucho más eficaz y duradero cuando se combina con el desarrollo de instituciones sociales que permitan seguir aumentando el poder de los pequeños propietarios. Diversas formas de cooperativas rurales tienen la posibilidad de generar el capital social y la organización colectiva en la que el poder puede desarrollarse. Las cooperativas rurales, sin embargo, no ocurren porque sí. Su desarrollo requiere diversas formas de apoyo político -por ejemplo, un marco jurídico apropiado y entidades de crédito que estén orientadas al apoyo de las cooperativas-. Como comentan Griffin et al. (en un contexto ligeramente diferente): "[...] Uno no puede simplemente dar tierra a los campesinos y luego abandonarlos, y esperar que todo esté bien” (p. 285).

El Reporte Sachs no discute, ni siquiera menciona, la reforma agraria. Las cooperativas son mencionadas, pero no se discuten como un elemento significativo en los programas de reducción de la pobreza. La reforma agraria y las cooperativas no son la panacea para la reducción de la pobreza. Sin embargo, es difícil ver cómo la pobreza puede reducirse en muchos países de bajos ingresos mientras que la propiedad de la tierra siga siendo muy desigual. $\mathrm{Y}$ algunas formas de instituciones sociales que aumentan el poder de los pobres son un componente necesario para el alivio de la pobreza -y las cooperativas parecen un buen candidato para esta función.

Hay otros ejemplos de formas en las que los programas de reducción de la pobreza pueden ser una manera de lograr la redistribución del ingreso y del poder. El modo en que se organizan los programas sociales es especialmente 
relevante. ${ }^{12}$ Como el Reporte Sachs y otros han subrayado, la escolarización es una parte importante de cualquier programa anti-pobreza. Sin embargo, prácticamente, poco se presta atención en el Informe a la estructura ni al contenido de la escuela y otros programas sociales. Es relativamente importante si las escuelas y clínicas de salud les son proporcionadas a los pobres o si los pobres se involucran en la creación y organización de estas instituciones sociales.

Las escuelas, después de todo, pueden tener la función de control social, así como la función de elevar los niveles de alfabetización y aritmética elemental. Además, es evidente que la mayor escolaridad no se traduce necesariamente en una reducción de la desigualdad de ingresos; durante los últimos decenios prácticamente la norma mundial ha sido más enseñanza y más alfabetización. Sin embargo, no se ha producido la correspondiente reducción en la desigualdad de ingresos. Por lo menos, para que la educación sea igualadora las escuelas deben ser iguales. Sin embargo, en todas partes la calidad y el contenido de la enseñanza difieren según la clase social de los estudiantes. Sin atender esta desigualdad, las escuelas no pueden desempeñar el papel central en la reducción de la pobreza que a menudo se les asigna.

Los centros de salud también pueden tener efectos muy diferentes, dependiendo de cómo esté n organizados. El éxito que se ha registrado en el estado indio de Kerala no sólo en lo que respecta a la salud de las mujeres en particular, sino también en cuanto a esperanza de vida y crecimiento de la población, ha sido en gran parte atribuido a la función de los propios pobres en el desarrollo de clínicas de salud y en la formulación de sus programas. Del mismo modo, parece que los instrumentos de las escuelas serían más eficaces para mejorar la situación de los pobres si los pobres participaran en su formación y funcionamiento. Al igual que con las cooperativas, este tipo de programas sociales son potencialmente valiosos no sólo para satisfacer las

\footnotetext{
${ }^{12}$ Estos breves comentarios sobre los programas sociales se desarrollan en el capítulo 7 de MacEwan (1999) y los comentarios posteriores sobre la formación a cambio de puestos de trabajo se detallan en el capítulo 8 .
} 
necesidades inmediatas con los servicios que proporcionan, sino también como instituciones para expandir el poder de los pobres. ${ }^{13}$

Como la discusión anterior sobre los incentivos fiscales para la inversión extranjera muestra, cualquier programa para elevar los ingresos, crear empleos y llevar una mayor igualdad, se enfrenta a problemas debido a la globalización. Cualesquiera que sean los efectos positivos o negativos resultantes de la mayor integración económica de las economías de varias naciones, una consecuencia es una disminución del 'espacio de política económica' de los gobiernos. ${ }^{14}$ La gran movilidad del capital en la época actual reduce la medida en que los gobiernos pueden dirigir la actividad económica, en particular la posibilidad de fomentar las inversiones que son más propensas a tener los beneficios sociales más grandes -es decir, que tienen más probabilidades de promover el desarrollo a largo plazo y la reducción de la pobreza-. Las desgravaciones fiscales han sido adoptadas por muchos gobiernos como un medio para fomentar la inversión - tal como se abogaba en el Reporte Sachs- pero, como se ha dicho anteriormente, son una herramienta insuficiente.

Sin embargo, en vista de la competencia, los gobiernos se ven obligados a estar preocupados por el problema de atraer y mantener inversiones. El capital es necesario para generar puestos de trabajo. Hay, sin embargo, diferentes maneras de competir, y las diferentes formas tienen distintas implicaciones para el desarrollo económico, en general, y para la distribución del ingreso, en particular. Tal vez la manera más importante para fomentar la inversión es crear un entorno económico general donde las oportunidades de inversión, sin concesiones especiales, atraigan a las empresas. En este sentido, la atención prestada al desarrollo de la infraestructura y la formación

\footnotetext{
${ }^{13}$ La experiencia en el estado de Kerala de la India tiene raíces complejas y no es simplemente el producto de políticas "iluminadas". También, como es cada vez más evidente, la experiencia social favorable en Kerala se debe, en parte importante, a las remesas de sus ciudadanos que trabajan en el extranjero, especialmente en los estados ricos en petróleo del Oriente Medio. No obstante, hay enseñanzas positivas que extraer de la experiencia de Kerala. Sin embargo, el Reporte Sachs nunca menciona Kerala.

${ }^{14}$ El concepto de 'espacio de política económica' en el contexto de la globalización se ha desarrollado, por ejemplo, en Gallagher (2005) y Wise (2007).
} 
en el Reporte Sachs es positiva. Sin embargo, si son necesarias las medidas concretas para fomentar la inversión, hay medidas que son preferibles a las desgravaciones fiscales.

Una de las políticas potencialmente favorables es un programa de adiestramiento para el trabajo. De diversas maneras, los gobiernos pueden ponerse de acuerdo para ofrecer formación a los trabajadores que son necesarios para los inversionistas a cambio de la creación de puestos de trabajo. Este tipo de programa puede reducir los costos de los inversionistas y por lo tanto servir al mismo tipo de función de incentivo, como los beneficios fiscales, pero las consecuencias son muy diferentes. Un programa de formación para el trabajo, en primer lugar, trae consigo una mejora de la fuerza de trabajo. Esto empuja a la economía en la dirección de crear más puestos de trabajo cualificados. En lugar de atraer a los inversores con mano de obra de bajos salarios, es un programa que coloca la carga de atraer a los inversionistas en la existencia de una mano de obra relativamente calificada. Por otra parte, en una época en que las empresas "cobran sus incentivos" y luego se van a otros lugares, un programa de formación para el trabajo asegura que algunas ganancias permanezcan aun cuando las empresas se retiren del lugar. Si bien los trabajadores pueden haber sido capacitados para trabajos específicos a una empresa en particular, el hecho de que hayan pasado por un programa de aprendizaje, que significa que han ampliado su capacidad de adaptación. Cuando las empresas se van, los trabajadores conservan tanto las habilidades específicas como las generales.

Se podrían dar otros ejemplos de las formas en que la política se vería afectada al dar un papel central a la distribución del ingreso en los esfuerzos para reducir la pobreza. Los programas de empleo, en particular, tendrían un mayor énfasis porque, como Khan (2005) y otros han sostenido, la expansión del empleo parece tener un mayor impacto en la reducción de la pobreza absoluta a través de su impacto en la distribución de los ingresos que a través de su impacto en el crecimiento. El reconocimiento de la importancia de la distribución del ingreso en la reducción de la pobreza puede provenir de ver esta capacidad de respuesta de la pobreza absoluta a una distribución más equitativa del ingreso. O puede venir de aceptar el argumento de que la po- 
breza en sí está, al menos en parte, definida en términos de distribución del ingreso. O el reconocimiento puede surgir de ambas fuentes. En cualquier caso, una vez que la importancia de la distribución del ingreso es reconocida, se hace necesario un tipo diferente de enfoque de política económica.

\section{Conclusión}

Es común que se plantee una objeción al énfasis en la distribución del ingreso en los programas de alivio de la pobreza mediante la pregunta de cuál de las dos opciones es preferible: Opción I. Un aumento de 10\% en los ingresos de los pobres combinado con un aumento de $20 \%$ en los ingresos de los ricos; o la Opción II. Una reducción de $10 \%$ en los ingresos de los pobres junto con una reducción de $20 \%$ de los ingresos de los ricos. En la opción II, la distribución es más igualitaria, pero es poco probable que alguien -ricos, pobres o responsable externo de la política económica- designe a la opción II como la preferible.

Pero el argumento implícito en esta cuestión se basa en la suposición errónea de que una distribución más equitativa de los ingresos de alguna manera está en conflicto con el crecimiento económico más rápido. La idea de que debe existir un equilibrio entre la igualdad y el crecimiento (el llamado balance equidad-eficiencia tiene una larga historia, y, paradójicamente, ha tenido el apoyo de todo el espectro ideológico. Los apologistas del status quo han argumentado que la desigualdad debe ser aceptada con el fin de lograr el crecimiento. Quienes se oponen al status quo han argumentado que la organización de la sociedad debe ser modificada, de manera fundamental, para que la igualdad sea posible con el crecimiento. Resulta que ambos se han equivocado.

El argumento de que el cambio económico se ve limitado por un balance entre la igualdad y el crecimiento, se basa principalmente en dos observaciones. Una observación es que los ricos tienden a ahorrar más que los pobres. Cuando se combina con el reconocimiento de que el ahorro es necesario para proveer los fondos de inversión para el crecimiento económico, esta observación tiende a apoyar la necesidad de que exista al menos alguna 
desigualdad -tal vez mucha desigualdad- a fin de lograr un crecimiento rápido. La segunda observación es que la desigualdad proporciona los incentivos que llevan a la gente a invertir (en capital físico y humano), tomar riesgos y trabajar duro. Se considera entonces que los programas que limitan la desigualdad, reducen los incentivos, perjudicando así el crecimiento. La conclusión de estas observaciones -que en términos económicos, la igualdad y el crecimiento parecen estar en conflicto entre sí- está a menudo apoyada por evidencias anecdóticas. En la era actual, por ejemplo, a menudo se cita la experiencia de China. ${ }^{15}$

No obstante, en los últimos años análisis empíricos sistemáticos han establecido que no existe relación general entre la desigualdad y el crecimiento económico. Los países que crecen más rápido no son más desiguales que los países que crecen lentamente. ${ }^{16}$ Por otra parte, hay evidencia anecdótica proporcionada por la experiencia de Corea del Sur y Taiwán (y quizá algunos otros países de Asia Oriental), donde se logró el rápido crecimiento al tiempo que se mantuvo una relativa igualdad. Estos estudios y estas experiencias no demuestran que el crecimiento y la igualdad necesariamente van juntos. En vez de eso, establecen que no existe una conexión firme en cualquier dirección -es decir, ni la igualdad ni la desigualdad conducen necesariamente a un crecimiento más rápido.

Lo que está claro es que la igualdad y el crecimiento pueden ser compatibles unos con otros. Depende de cómo se logra el crecimiento, qué tipo de

\footnotetext{
${ }^{15}$ A veces se hace referencia a la curva de Kuznets como apoyo a este argumento, y se afirma que al menos en las primeras etapas de los países el crecimiento económico debe llegar a ser más desigual., Sin embargo, la curva de Kuznets a lo sumo describe una tendencia general, y no una relación absoluta. Incluso como una tendencia general la existencia de la curva es cuestionable, y, en la medida en que la curva existe, su interpretación es compleja. Por otra parte, Kuznets veía la relación como algo que refleja no sólo un fenómeno económico, sino también como algo que implica un grado considerable de acción política. Para una discusión más completa de la importancia de la curva de Kuznets en este contexto y de estos puntos en particular, véase MacEwan (1999:74-82).

${ }^{16}$ Véase, en particular, Alesina y Rodrik (1994) y Persson y Tabellini (1994). Aunque otros estudios han cuestionado sus resultados, la conclusión general de estos análisis se mantiene: que no existe una base empírica clara sobre la que afirman que la igualdad y el crecimiento en general están en conflicto entre sí.
} 
instituciones se establecen y los tipos de políticas que se adopten. ${ }^{17} \mathrm{Si}$ bien el ahorro y los incentivos que pueden ser generados por la desigualdad son parte de la historia del crecimiento, son sólo partes y con frecuencia parecen ser compensados por otros factores. Por ejemplo, en las experiencias de Corea del Sur y Taiwán está generalmente reconocido que los factores de una temprana reforma agraria y una extensiva inversión en educación fueron importantes para promover la igualdad relativa y un rápido crecimiento económico. La reforma agraria, al extirpar el poder de una clase terrateniente, parece haber creado el espacio político para una política industrial efectiva; la educación parece haber proporcionado una base para un rápido aumento de la productividad. Otros factores también pueden contribuir a una relación positiva igualdad-crecimiento. Alesina y Rodrik (1994) hacen hincapié en la estabilidad política que viene con la igualdad relativa. Murphy et al. (1989) han sostenido que la igualdad relativa tiende a generar una demanda de bienes producidos en masa y, por tanto, que se estimula el desarrollo industrial. Además, hay algunas razones para creer, junto con Habakkuk (1962), que el aumento de los salarios (que tienden a significar más igualdad) puede inducir el progreso tecnológico más rápido. Por último, resulta que los incentivos que emanan de la desigualdad pueden dar incentivos negativos en lugar de positivos, $y$, dentro de un marco institucional adecuado, los ahorros de los individuos ricos pueden ser relativamente poco importantes.

Una vez que queda claro que el crecimiento y la igualdad son posibles y que la reducción de la pobreza depende tanto de aumentar los ingresos como de reducir la desigualdad, el problema se transforma en cual es la estrategia económica a seguir. Es aquí que el proyecto de Metas de Desarrollo

\footnotetext{
${ }^{17}$ La discusión que sigue está más ampliamente desarrollada en MacEwan (1999, especialmente capítulo 3). El argumento aquí es que el rápido crecimiento económico puede lograrse al tiempo que un país sigue siendo relativamente igual en cuanto a la distribución del ingreso, como fue el caso, por ejemplo, en Corea del Sur desde hace muchos años. No se afirma que durante un largo período de rápido crecimiento un país pueda llegar a ser más y más igualitario, en términos de distribución del ingreso. Esto puede ser posible, pero no es necesario para este argumento. El punto importante es: tenemos evidencia suficiente para rechazar la idea de que sea necesario un balance entre crecimiento e igualdad, y que para alcanzar un rápido crecimiento es necesario que un país sea muy desigual.
} 
del Milenio parece ser negligente. Al no prestar atención a la distribución del ingreso, el proyecto del Milenio no puede generar una estrategia que se mueva con mayor eficacia hacia un crecimiento combinado con equidad.

Independientemente de cómo se define la pobreza -tanto en términos de condición absoluta o relativa de las personas o, como se ha sostenido, por una combinación de condiciones relativas y absolutas- la distribución del ingreso (y la distribución de la riqueza) no puede excluirse de esta consideración. Así como la pobreza absoluta es aberrante en términos de valores humanos básicos y como un asunto de justicia social, también lo es la gran desigualdad en la distribución del ingreso -la desigualdad que existe en gran parte del mundo de hoy.

\section{BibLiografía}

Alesina, A. y D. Rodrik, "Distributive politics and economic growth", Quarterly Journal of Economics, vol. 109, núm. 2, 1994, pp. 465-490.

Amsden, A., Asia's Next Giant: South Korean and Late Industrialization, Oxford, Oxford University Press, 1989.

Atack, J. y P. Passell, A New Economic View of American History, 2a. edición, Nueva York/Londres, W.W. Norton and Co., 1994.

Banuri, T., "Macropolicy or social mobilization? Approaches to poverty eradication", Environment, vol. 47, núm. 9, 2005, pp. 39-43.

Beer, L. y T. Boswell, "The resilience of dependency effects in explaining income inequality in the global economy: a cross-national analysis, 1975*1995", Journal of World-Systems Research, vol. VII, núm. 1, 2002, pp. 30-59. Disponible en: <http://jwst.ucr.edu/archive/vol8/number1/ pdf/jwsr-v8n1-beerboswell.pdf> (consultado el 12 de octubre de 2007).

Bowles, S., "Capitalist development and educational structure", World Development, vol. 6, núm. 6, 1978, pp. 783-796.

Cahill, M.B., "Is the human development index redundant?", Eastern Economic Journal, vol. 31, núm. 1, 2005, pp. 1-5.

Conferencia de las Naciones Unidas sobre Comercio y Desarrollo (UNCTAD), World Investment Report 2004, Nueva York/Ginebra,Naciones Unidas, 2004. 
Disponible en: <http://www.unctad.org/Templates/WebFlyer.asp?intIte $\mathrm{mID}=3235 \&$ lang $=1>$ (consultado el 12 de octubre de 2007).

DeMello, L.R.,Jr., "Foreign direct investment in developing countries and growth: a selective survey", The Journal of Development Studies, vol. 34, núm. 1, 1997, pp. 1-34.

Drèze, J. y A. Sen, India: Economic Development and Social Opportunity, Oxford, Oxford University Press, 1995.

Elson, D., "Male bias in macroeconomics: the case of structural adjustment", en D. Elson (ed.), Male Bias in the Development Process, Manchester, Manchester University Press, 1991.

European Social Statistics (Eurostat), European Social Statistics: Income, Poverty and Social Exclusion, Eurostat, Luxembourg, 2000.

Freebairn, D.K., "Did the green revolution concentrate incomes? A quantitative study of research reports, World Development, vol. 23, núm. 2, 1995, pp. 265-279.

Gallagher, K.P., Putting Development First: The Importance of Policy Space in the WTO and IFIs, Londres, Zed Books, 2005.

Galor, O.; O. Moav y D. Vollrath, "Land inequality and the origin of divergence and overtaking in the growth process: theory and evidence," febrero 29, 2004. Disponible en: <http:// papers. ssrn.com/sol3/papers.cfm?abstract_ id=317934\#PaperDownload $>$ (consultado el 26 de septiembre de 2007).

Griffin, K.; A. Rahman Khan y A. Ickowitz, "Poverty and the distribution of land", Journal of Agricultural Change, vol, 2, núm. 3., 2002, pp. 279330. Disponible en: <http://www.blackwell-synergy.com/doi/pdf/ 10.1111/1471-0366.00036> (consultado el 14 de octubre de 2007).

Habakkuk, H.J., American and British Technology in the Nineteenth Century: The Search for Labour-Saving Inventions, Cambridge, Cambridge University Press, 1962.

Jiggins, J., "Gender-related impacts and the work of the International Agricultural Research Centres", World Bank, Consultative Group on International Agriculture Research Study Paper no. 17, 1986.

Khan, A.R., Growth, Employment and Poverty: An Analysis of the Vital Nexux Based on Some Recent UNDP and ILO/SIDA Studies, Nueva York/Geneva, Programa de las Naciones Unidas para el Desarrollo (PNUD)/Oficina Internacional del Trabajo, 2005. 
MacEwan, A., Neo-Liberalism or Democracy? Economic Strategy, Markets and Alternatives for the 21st Century, Londres, Zed Books, 1999.

Marx, K., "Wage-Labour and Capital", en KarlMarx: Selected Workes in Two Volumes, vol. I, Moscow, Marx-Engels-Lenin Institute, s/f [1847] (Reimpreso por V. Adoratsky (ed.), Nueva York, International Publishers).

Mattar, J.; J.C. Moreno-Brid, W. Peres, "Foreign investment in Mexico after economic reform," Estudios y Perspectivas, México, Comisión Económica para América Latina y el Caribe (CEPAL), Sede Subregional de México, 2002. Disponible en: < http://www.networkideas.org/featart/sep2002/Mexico. pdf $>$ (consultado el 12 de octubre de 2007).

McGillivrary, M., "The human development index: yet another redundant composite development indicator?", World Development, vol. 19, núm. 10, 1991, pp. 1461-1468.

Morley, S.A., "The effects of growth and economic reform on income distribution in Latin America", CEPAL Review, núm. 71, 2000, pp. 23-40. Disponible en : <http://www.eclac.org/publicaciones/xml/3/20153/ lcg2060i_morley.pdf> (consultado el 12 de octubre de 2007).

Murphy, K.; A. Shleifer y R. Vishny, "Income distribution, market size, and industrialization", Quarterly Journal of Economics, vol. CIV, núm. 3, 1989, pp. 537-564.

Pant, S.K.C., "Discurso del Seminario 'Globalización y Desarrollo Humano"” organizado por Indian Council for Research on International Economic Relations/United Nations Development Programme (ICRIER/UnDP) en el India Habitat Centre, Nueva Delhi, 14 de Julio, 1999. Disponible en: < http:/ / planningcommission.nic.in/aboutus/speech/dch35.htm> (consultado el 5 de septiembre de 2007).

Persson, T. y G. Tabellini, "Is Inequality Harmful for Growth?”, American Economic Review, vol. 84, núm. 3, 1994, pp. 600-621.

Pomeranz, K., The Great Divergence: China, Europe and the Making of the Modern World Economy, Princeton, Princeton University Press, 2000.

Programa de las Naciones Unidas para el Desarrollo (PNUD), Human Development Report 1990, Oxford/Nueva York, Oxford University Press, 1990.

$\longrightarrow$, Human Development Report 2006, Beyond Scarcity: Power, Poverty and the Global Water Crisis, Houndmills/Nueva York, Palgrave Macmillan, 2006. 
Proyecto del Milenio de las Naciones Unidas, Investing in Development: A Practical Plan to Achieve the Millennium Development Goals (The Sachs Report), Londres/Sterling, Va., Earthscan, 2005. Disponible en: <http://www. unmillenniumproject.org/ reports/index.htm> (consultado el septiembre 17 de 2007).

Sahlins, M., Stone Age Economics, Chicago/Nueva York, Aldine Atherton, Inc., 1974.

Sen, A., Poverty and Famines: An Essay On Entitlement and Deprivation, Oxford, Oxford University Press. 1981.

, "Poor, Relatively Speaking", Oxford Economic Papers, Nueva Serie, vol. 35, núm. 2, 1983, pp. 153-169.

—, Commodities and Capabilities, Nueva Delhi, Oxford University Press, 1987.

—, Inequality Reexamined, Oxford, Oxford University Press, 1992.

Smith, A., An Inquiry into the Nature and Causes of the Wealth of Nations, Nueva York, The Modern Library, Random House.1937 [1776].

Stanton, E., "Accounting for inequality: a proposed revision of the human development index," Political Economy Research Institute, University of Massachusetts Amherst, Working Paper Series no. 119, 2006. Disponible en: <http://www.peri.umass.edu/fileadmin/pdf/working_papers/working papers_101-150/WP119.pdf> (consultado el 15 de octubre de 2007).

Sutcliffe, B., "A converging or diverging world?", Department of Economic and Social Affairs, United Nations, Working Paper no. 2, 2005. Disponible en: <http://www.un.org/esa/desa/papers/2005/wp2_2005.pdf> (consultado el 27 de septiembre de 2007).

Tendler, J., "The fear of education", Trabajo presentado en la 50ª Reunión de Aniversario del Banco do Nordeste, Fortaleza, 19 de julio de 2002. Disponible en: <http://www.oecd.org/dataoecd/43/40/2489865.pdf> (consultado el septiembre 26 de 2007).

te Velde, D.W., "Foreign direct investment and income inequality in Latin America: Experiences and policy implications", Londres, Overseas Development Institute, 2003. Disponible en: <http://www.odi.org. uk/IEDG/meetings/FDI_feb2003/fdi_la_dwtv.pdf $>$ (consultado el 12 de octubre de 2007). 
Tsai, P.-L., "Foreign direct investment and income inequality: further evidence," World Development, vol. 23, núm. 3, 1995, pp. 469-483.

Wade, R., Governing the Market: Economic Theory and the Role of Government in East Asian Industrialization, Princeton, Princeton University Press, 1990.

Wise, T., "Policy Space for Mexican Maize: Protecting Agro-biodiversity by Promoting Rural Livelihoods", Global Development and Environment Institute, Working Paper no. 07-01, 2007. Disponible en: <http://www. ase.tufts.edu/gdae/Pubs/wp/07-01MexicanMaize.pdf $>$ (consultado el 14 de octubre de 2007). 